\title{
MALAS RELACIONES: PRENSA Y MOVIMIENTO ESTUDIANTIL UNIVERSITARIO EN CHILE A FINES DE LA DICTADURA E INICIOS DE LA TRANSICIÓN DEMOCRÁTICA (C. 1988 - C. 1998)
}

DOI: http://dx.doi.org/10.1590/2236-3459/77343

\author{
Pablo Toro Blanco \\ Universidad Alberto Hurtado, Santiago de Chile/Santiago, Chile
}

\section{$\cos 80$}

\begin{abstract}
Resumen
El movimiento estudiantil universitario chileno fue activo opositor a la dictadura civil y militar encabezada por Augusto Pinochet, usando diversos repertorios de acción, copando espacios propiamente universitarios como también públicos e implementando acciones en busca de objetivos propios o aliándose con otros colectivos para propósitos de orden político mayor. Una vez producida la salida pactada de la dictadura, el movimiento debió reconstruir su agenda, modos de organización y formas de acción en una democracia transicional preocupada de aminorar la acción de los movimientos sociales en aras de la gobernabilidad. Este texto busca interpretar algunos hitos de la relación que se estableció entre prensa escrita y movimiento estudiantil universitario a través del período en estudio.
\end{abstract}

Palabras clave: Chile, movimiento estudiantil, transición, emociones, prensa.

\section{MÁS RELAÇÕES: IMPRENSA E O MOVIMENTO DO ESTUDANTES UNIVERSITÁRIOS CHILENOS NO FINAL DA DITADURA E COMEÇOS DE TRANSIÇÃO DEMOCRÁTICA (C. 1988 - C. 1998)}

\section{Resumo}

O movimento estudantil chileno foi um adversário ativo da ditadura civil-militar liderado por Augusto Pinochet, utilizando diferentes repertórios de ação, capturando universidade real como espaços públicos e implementação de ações em busca de si mesmos ou aliar-se com outros grupos para fins de objetivos políticos maior. Uma vez produzido a solução acordada da ditadura, o movimento teve de reconstruir sua agenda, modos de organização e formas de ação em uma democracia de transição preocupada em diminuir a ação dos movimentos sociais, no interesse de uma boa governabilidade. Este texto procura interpretar alguns marcos na relação estabelecida entre imprensa e movimento estudantil universitário durante todo o período do estudo.

Palavras-chave: Chile, movimento estudantil, transição, emoções, imprensa. 


\title{
BAD RELATIONSHIPS: PRESS AND STUDENT MOVEMENT IN CHILE AT THE END OF DICTATORSHIP AND THE BEGINNINGS OF DEMOCRATIC TRANSITION (C. 1988 - C. 1998)
}

\begin{abstract}
The Chilean university student movement was an active opponent of the civic-military dictatorship led by Augusto Pinochet, using diverse repertoires of action, copying spaces properly university as well as public and implementing actions in pursuit of their own objectives or allying with other groups for higher political purposes. Once the agreed output of the dictatorship had been produced, the movement had to rebuild its agenda, modes of organization, and forms of action in a transitional democracy concerned with lessening the action of social movements for the sake of governance. This text seeks to interpret some milestones of the relationship that was established between the written press and university student movement throughout the study period.
\end{abstract}

Keywords: Chile, student movement, transition, emotions, press.

\section{MAUVAISES RELATIONS: PRESSE ET MOUVEMENT DU ÉTUDIANTS UNIVERSITAIRES AU CHILI À LA FIN DE LA DICTATURE ET DÉBUTS DE TRANSITION DÉMOCRATIQUE (C. 1988 - C. 1998)}

\section{Résumé}

Le mouvement étudiant chilien était un adversaire actif de la dictature civile-militaire dirigé par Augusto Pinochet, en utilisant différents répertoires d'action, capturant l'université réelle des espaces publics et la mise en œuvre des actions à la recherche d'eux-mêmes ou une alliance avec d'autres groupes à des fins d'objectifs politiques plus grand. Une fois produit la solution convenue de la dictature, le mouvement a dû reconstruire son ordre du jour, les modes d'organisation et formes d'action dans une démocratie de transition inquiet diminuer l'action des mouvements sociaux dans l'intérêt de la bonne gouvernance. Ce texte vise à interpréter certains jalons dans la relation établie entre la presse et le mouvement étudiant à l'université pendant toute la période d'étude.

Mots-clés: Chili, mouvement étudiant, transition, émotions, presse. 


\section{Introducción}

I movimiento estudiantil universitario ha tenido una importante presencia
mediática en Chile durante los años recientes. En 2011, bajo el gobierno
derechista de Sebastián Piñera, movilizaciones callejeras de gran convocatoria coparon las principales avenidas de las ciudades más importantes del país. Al amparo de las demandas por educación pública, gratuita y de calidad (herencia de lo planteado por los estudiantes secundarios durante la "revolución de los pingüinos" de 2006, que puso en jaque al gobierno de Michelle Bachelet), los universitarios ocuparon parte importante de la agenda noticiosa.

En el ciclo de movilizaciones estudiantiles que durante 2011 sostuvieron los estudiantes (tanto de universidades estatales como privadas) fue frecuente la ocupación de la Alameda, la principal vía de Santiago, por parte de numerosas marchas. Frente a ellas, hubo una pluralidad de posturas en los medios de comunicación escritos (que podría calificarse de restringida), desafiada consistentemente por el acelerado avance y difusión de las redes sociales y otras formas de comunicación que han buscado oponerse a un núcleo de discursos generalmente carente de matices mayores. En el conjunto de las reacciones editoriales de la prensa, destacó el tono predominante que transmitieron las columnas de opinión e informaciones del periódico El Mercurio, el principal medio escrito del país. El énfasis del discurso hacia los estudiantes fue de carácter admonitorio, "exhortando al cumplimiento de la norma legal" (MARÍN NARITELLI, 2014, p. 174), al mismo tiempo que, mediante la cobertura noticiosa del diario, se configuraba la imagen de un movimiento estudiantil con rasgos anárquicos y, en ocasiones, rayanos en lo delictual. Ahora bien, cabe destacar que esa inducción a la continencia juvenil era ejercida frente a un escenario de movilización que había alcanzado una masividad tal que, junto con la ya mencionada profusión de formas de comunicación alternativas, dificultaba que ese discurso tuviera el rendimiento y eficacia que alcanzó en otros contextos como, por ejemplo, durante los años de la dictadura de civiles y militares encabezada por Augusto Pinochet entre 1973 y 1990 o, como se verá en estas páginas, en los primeros años de la transición a la democracia.

En función de lo recién señalado es que cobra sentido el título con el que se inicia este texto. Mediante una revisión a la cobertura de medios escritos a algunos hitos específicos de la evolución del movimiento estudiantil en la década de 1990, se plantea en estas páginas, de manera tentativa, que la imagen transmitida por los principales periódicos chilenos sobre los jóvenes universitarios movilizados se construyó, prioritariamente, a través de dos estrategias, que obedecieron a razones de distinto calado. En un primer caso, es posible argumentar que hubo un silenciamiento respecto a las actividades de los estudiantes universitarios (o, al menos, menciones selectivas hechas a partir de intereses ideológicos muy evidentes), hecho que constituyó parte de una tendencia estructural del proceso de transición política en Chile. En segundo lugar, es plausible sostener la existencia de una línea de continuidad respecto a particularidades del discurso periodístico prevaleciente en dictadura, aunque con algunos matices que se analizan más adelante.

Para el cumplimiento de los propósitos señalados, este texto se divide en dos partes principales. En la primera se presenta una mirada sintética respecto al desarrollo de la prensa 
escrita en Chile y al impacto que la dictadura pinochetista ejerció sobre ella. Como complemento, se rescatan algunos conceptos orientadores generales y de contextualización para el análisis de una selección de textos de algunos de dichos medios escritos. En segundo lugar, se explora en torno a coyunturas específicas en las que medios de prensa escrita elaboraron discurso con respecto a los estudiantes universitarios como actores insertos en un nuevo esquema general de conflicto (a saber, la transición democrática).

\section{Una mirada panorámica a la prensa chilena en dictadura y sus legados para el período de transición. Elementos de contexto y análisis}

No ha sido del todo azaroso que se haya configurado una suerte de imaginario compartido respecto a una "edad dorada" periodística en Chile, la que habría estado constituida por un escenario plural de medios en la esfera pública antes de la llegada de la dictadura en 1973. Los números avalan en parte esta afirmación. Así, pues, en 1972 había diez periódicos que tenían circulación a nivel nacional, perteneciendo a un rango amplio de sectores de opinión. Por el contrario, hacia 1984 ese número se había reducido a cinco. Esta disminución, fruto evidente de la censura política sobre los medios asociados a la Unidad Popular, también estuvo acompañada de una concentración en la propiedad de los medios de información escritos. (SANTA CRUZ, 2015, p. 175-176). Contrariamente a lo que se podría haber esperado, al hacer una clasificación de la prensa de acuerdo a filiación política es posible notar que la década de 1990, terreno de la transición democrática, marcó una mantención de la hegemonía de las plataformas periodísticas de derecha. De los diarios de circulación nacional, en el período de la dictadura hubo solamente tres que podrían contarse como de oposición y que, pese al cambio de régimen supuestamente favorable para ellos desde 1990, no lograron perdurar. (DIBAM, 2006, p. 40). Así, hubo varios años de la década en que, lisa y llanamente, no existieron periódicos de circulación nacional que no fueran de tendencia derechista (salvo el de gobierno, La Nación). Es llamativo constatar que los medios escritos que habían difundido las ideas opositoras a la dictadura no recibieron un apoyo consistente de parte del nuevo gobierno democrático para poder solventar su subsistencia y, mediante ésta, el aseguramiento de un mayor grado de pluralidad periodística. En estricto sentido, no sería exagerado concluir que "nunca existió una política de ayuda hacia los medios progresistas" (GUMUCIO; PARRINI, 2009, p. 304), con la que pudieran hacer frente a sus deudas (contraídas en el contexto de su expansión durante el período de clímax electoral que estuvo marcado por el plebiscito de octubre de 1988 y las elecciones presidenciales de 1989). Ello marcó una diferencia (tanto procedimental como moral y política, ciertamente) con las maniobras mediante las cuales la dictadura militar aseguró la sustentabilidad de El Mercurio tras la gran crisis económica de la primera mitad de la década de 1980. No obstante, también es necesario considerar que la dinámica de la propia industria periodística fue un factor que atentó contra la pluralidad de medios, dado que los periódicos que jugaron un papel destacado en su enfrentamiento con la dictadura militar, sobre todo a partir del horizonte transicional desde 1987, fueron víctimas de su poca capacidad para transitar hacia formatos que les permitieran exhibir "atributos de diferenciación no políticos" para competir por un mercado lector crecientemente desligado del eje del conflicto político. En tal sentido, carecieron de 
adaptabilidad a un entorno periodístico cada vez más orientado a las demandas (en creciente segmentación) de la sociedad civil, en un acelerado proceso de transformación cultural (SUNKEL, 1992a, p. 35). Como ejemplo de esta necesidad de acoplarse a "los intereses de la gente" puede considerarse el hecho de que en 1996 prácticamente la mitad de las páginas de La Nación, el diario del gobierno, era ocupada por el suplemento deportivo diario "Triunfo Diario". Siendo un medio oficialista, era bastante poco informativo de los sucesos cotidianos referentes a movimientos sociales, ya sea porque las movilizaciones no fueran numerosas 0 porque, lisa y llanamente, las silenciaba.

Un escenario como el descrito condiciona seriamente la potencialidad del análisis que pueda hacerse respecto a la construcción de un imaginario periodístico de determinados actores, especialmente aquellos asociados a movimientos de ruptura por su orientación tanto política como generacional, como es el caso de los estudiantes universitarios organizados. De tal modo, en una arena periodística sumamente limitada en términos de la propiedad de los medios y su orientación ideológica, la construcción de discurso respecto al movimiento estudiantil presentó ciertas constantes, que podrían remontarse, en el caso de algunos periódicos, a una larga relación de polémica y confrontación con los estudiantes universitarios. Así se dio, por ejemplo, en el caso específico del principal diario nacional, que arrastraba décadas de distancia (cuando no abierta oposición) respecto al movimiento estudiantil universitario: la famosa frase "El Mercurio miente", inolvidable ícono de la toma de la Casa Central de la Universidad Católica en 1967, en el contexto del movimiento de reforma universitaria que vivía el país en esa década agitada, lesionó mediáticamente de manera profunda al principal (supuesto) capital de ese medio: su tono y contenido de alegada objetividad, por sobre el bien y el mal de las coyunturas históricas, que ha sido conceptualizado tradicionalmente como "tono mercurial". De tal modo, sucedió con "apenas un lienzo ubicado estratégicamente, que abofeteó el prestigio del diario considerado como el más serio del país". (DOUGNAC et al., 2009, p. 20). En los años de la Unidad Popular (1970-1973), este periódico brindó cobertura a las movilizaciones estudiantiles de los grupos opositores al gobierno socialista, destacando especialmente la cercanía que se expresó, a través de sus páginas, con la Feuc (Federación de Estudiantes de la Universidad Católica de Chile), una vez que la conducción de dicha organización estudiantil cayó en manos del gremialismo, testimonio universitario de las posiciones de derecha.

Un elemento que es importante considerar para apreciar las relaciones entre movimientos sociales y prensa periódica (particularmente aquella que, con mayores o menores matices, reprodujo los conceptos políticos propios de la derecha que sustentó a la dictadura), es el clivaje que se puede notar, mirado en un plazo más amplio, entre los tipos de discursos asociados a las pretensiones de incidencia en la opinión pública que cada medio empleó. Esto nos parece importante, en la medida que proyecta sobre el período de transición algunos posibles elementos de continuidad respecto al tratamiento dado a fenómenos de crítica social como, por ejemplo, los movimientos estudiantiles. Así, la articulación de tonos editoriales y agendas de interés dio lugar a ciclos de exacerbación del lenguaje como herramienta de choque, denuncia y ofensa, en términos que han sido posteriormente mirados con ojos críticos por analistas del rol de la prensa tanto en el conflicto de la Unidad Popular como en su papel 
en años de dictadura. En sus antípodas, se consolidó una modalidad de discurso periodístico que buscó establecer hegemonía mediante un conjunto de operaciones articuladas, las que lograron configurar (salvo mínimos desvíos ocasionales) un estilo de secuencia, profundidad temporal ( $\mathrm{y}$, con ésta, legitimidad), además de seriedad y parsimonia formal: el "tono mercurial", al que se ha aludido ya. Esta estructura dual, que contenía una "prensa seria" junto con una "prensa ariete" (tanto en sus modalidades de derecha como de izquierda) fue considerada, en su momento, como un factor importante de debilitamiento del régimen democrático, de acuerdo al análisis del sociólogo Patricio Dooner. Esa dualidad de estilos y discursos se hizo presente también en la propia prensa opositora a Pinochet: mientras el diario La Época buscó perfilarse como un medio serio, de lenguaje contenido y reflexivo (aunque transparente en su filiación política con las fuerzas opositoras a la dictadura), el semanario Fortín Mapocho desempeñó el papel de un ariete periodístico poblado de adjetivos, declamaciones, denuncia abierta y confrontación explícita contra el régimen, usando un amplio repertorio estilístico que incluyó el humor y la sátira política.

En una mirada retrospectiva a su ejercicio como periodista de oposición en Chile durante la dictadura civil-militar encabezada por Augusto Pinochet (1973-1990), el columnista Ascanio Cavallo recordaba los riesgos de la degradación del lenguaje y sus consecuencias nefastas cuando, en el marco de los medios de prensa, se formulan epítetos insultantes y miradas descalificadoras al enemigo construido desde las páginas de los tabloides. Comentaba Cavallo, en su discurso de incorporación a la Academia Chilena de la Lengua en 2014, que

[...] en solo un par de años pasamos del titular de un diario de izquierda que calificaba a los ministros de la Corte Suprema como "viejos de mierda" al titular de un diario de derecha que describía una masacre con una frase de escalofrío: "miristas se matan como ratas". La prensa chilena de los 70 contribuyó a la tragedia nacional casi tanto como los grupos armados, la policía y la justicia, aunque siempre se percibió a sí misma a la zaga de la convulsión política. (CAVALLO, 2014) ${ }^{1}$.

Complementaba su juicio con una alusión al odio como pasión destructiva y al poder político que puede llegar a tener. Graficaba su idea mediante una cita a los "dos minutos de odio" concedidos a la población del distópico mundo imaginado por George Orwell en su libro 1984. (CAVALLO, 2014, p. 81-82).

Las reflexiones de Cavallo, realizadas desde una importante distancia temporal, parecen ser muestra de un juicio sobre el periodismo en que se asumía la existencia de un canon que debía guiar a la prensa. Es difícil no considerar como un elemento ordenador del debate periodístico del período post-dictadura al prurito de la moderación y del control emocional. En tal sentido, consideramos que una comprensión más afinada del discurso de

\footnotetext{
${ }^{1}$ Con la referencia al titular de un diario de derecha (La Segunda, del grupo Edwards, propietario de El Mercurio), Cavallo alude a la tristemente célebre operación (coordinada entre los servicios de policía política de Chile, Brasil y Argentina) en que dicho periódico participó entregando información falsa para encubrir el asesinato y/o desaparición de varios militantes del Movimiento de Izquierda Revolucionaria (MIR) fuera de Chile. El encabezado exacto de la edición de La Segunda del día 24 de julio de 1975 era "Exterminados como ratones. 59 miristas chilenos caen en operativo militar en Argentina".
} 
los medios de prensa frente al movimiento estudiantil se puede ver enriquecida por una referencia breve a dos asuntos conceptuales: la noción de imaginario social y algunas categorías propias del campo de la historia de las emociones. Para ambos casos, resulta común el hecho de ser problemas cruciales de una forma de entender la historia que, sin desconocer los condicionantes materiales a los que se brindó atención privilegiada durante buena parte del siglo XX, atiende a los significados socialmente compartidos de conceptos que forman los vínculos colectivos. Así, nuestro problema se reconoce como inscrito en un horizonte de estudio relacionado con

[...] el "giro lingüístico [que] en los estudios históricos de décadas recientes ha sido parte de un esfuerzo por romper el determinismo inherente en los anteriores enfoques socioeconómicos y enfatizar el papel de los factores culturales, entre los cuales el lenguaje ocupa un lugar clave. (IGGERS, 2012, p. 214-215).

Con respecto al primer asunto (o sea, la idea de imaginario social), entendiendo como referencia primera de muchos autores a los conceptos planteados por Cornelius Castoriadis en su texto seminal La institución imaginaria de la sociedad (1975), que abrió una nueva discusión sobre las limitaciones de analizar la ideología y los discursos como meros productos de la esfera de lo material, numerosos autores han reflexionado sobre cómo es que, al pensarse la sociedad en un ejercicio mediante el cual se funda en sus condiciones de posibilidad, se articulan imaginarios sociales que la instituyen, le brindan cohesión y eficacia como orden o cosmovisión. Por ejemplo, desde un énfasis en el perfil de lo imaginario como sustento de la Nación como forma histórica propia de la Modernidad, Benedict Anderson ha problematizado el lazo discursivo multidimensional (escrito, visual, hablado, sonoro) que rodea y une a determinados colectivos y aspira a naturalizar dicha afiliación. Es especialmente explícito que la producción de discursos como los que genera la prensa contribuye a la formación de dichos imaginarios, en tanto como lenguaje construyen y son construidos en un plano comunicativo que asume la existencia de una comunidad de lectores. Es a ellos a quienes (o para quienes) se traza, con familiaridad, los bordes de lo normal y los límites de lo natural, en una operación que no puede explicitarlos pues el lenguaje mismo los instituye como implícitos. De tal modo, mediante giros retóricos y modelos de estructuración de la información, así como también a través de énfasis editoriales, cualificaciones, cuantificaciones, adjetivaciones y apelaciones interpersonales o colectivas, se opera un ejercicio de institución de la realidad o, al decir de Charles Taylor, el despliegue de "una idea de las expectativas normales que mantenemos los unos respecto de los otros, de la clase de entendimiento común que nos permite desarrollar las prácticas colectivas que informan nuestra vida social". (TAYLOR, 2006, p. 38). En tal sentido, los imaginarios sociales, que "actúan como sustento de conservación, cambio y filtro de una realidad significante multidimensional" (DITTUS, 2008, p. 19), son elaboraciones que, al expresarse en soportes como el del discurso periodístico, contienen afirmaciones explícitas que se dan por necesarias y naturales para "describir" lo que es la "realidad" (cuyas afirmaciones cimeras suelen ser los lenguajes expertos, como el de la economía o las normativas legales), al mismo tiempo que portan juicios o posicionamientos de acuerdo a un "sentido común" emocional que se asume también como compartido. 
Respecto al segundo punto y formulado en términos breves, la atención concedida al sustrato emocional normativo presente en editoriales e informaciones periodísticas permitiría apreciar la complejidad del proceso de construcción de imaginarios sociales por parte de la prensa: reiteración de términos, adjetivaciones, inducciones e interpelaciones al lector (ya sea mediante el texto o las imágenes) a suscribir un "sentido común" que intentaría ser convincente tanto en el nivel de la ideología (explicitada como pensamiento reflexivo) como en el de la apreciación compartida en base a un horizonte emocional común. En tal sentido puede resultar de utilidad considerar la noción de "emocionología", formulada en 1985 por Peter Stearns y Caroline Stearns, como un "conjunto de estándares emocionales colectivos en los que agentes sociales e instituciones promueven o prohíben ciertos tipos de emociones 0 , al contrario, otras les resultan indiferentes". (STEARNS, 1985, p. 813) ${ }^{2}$. En el despliegue de un determinado estilo de discurso de prensa escrita sería posible encontrar, creemos, ciertas tendencias a promover en los lectores continencia política y cautela social, a partir de la promoción de una sensación de riesgo e inseguridad. En estricto sentido, no es aventurado sostener que la expansión de la idea de "seguridad ciudadana", madurada y difundida en los primeros años de la transición, le debió una buena parte de su eficacia al despliegue de los medios escritos, los que propalaron un discurso en el que abundaban las tonalidades que inducían al miedo (a la delincuencia, la juventud, el extremismo o el caos). En subsidio de esta noción respecto a que el marco histórico en el que se desarrolló la transición estuvo marcado por inducciones a emociones funcionales a su finalidad declarada (la "reconciliación nacional"), podría considerarse el tono general que las autoridades políticas intentaron darle a su gestión gubernamental: cuidadosas puestas en escena de reacciones desapasionadas y exentas de agresividad y, por el contrario, plenas de constricción como, por ejemplo, quedó graficado en las lágrimas del presidente Patricio Aylwin en marzo de 1991 al dar a conocer, mediante cadena nacional de radio y televisión, la entrega del Informe Rettig (destinado a establecer una verdad histórica oficial y consensuada sobre las violaciones a los derechos humanos bajo la dictadura). Se trasunta así que las emociones tienen, en efecto, un impacto político que rebasa los límites de una supuesta racionalización integral de la cosa pública en el mundo contemporáneo. Por el contrario, se aprecia una expectativa de conductas propias de liderazgos empáticos (FREVERT, 2011) que, además para el caso en estudio, se habría visto promovida por el lenguaje que reforzaban los distintos medios de comunicación social.

Aquella suerte de mandato de "realismo político" de parte del periodismo escrito al que nos hemos referido era previsto, antes del paso del poder de militares a civiles materializado en marzo de 1990, como un imperativo. Así, se sostenía que

abrumados por la falta de libertad de los últimos tres lustros, la tentación de eliminar todas las cortapisas es muy grande. Queremos abrir todas las ventanas para llenar nuestros pulmones de oxígeno. Pero ¡cuidado! Que no son pocos los envenenadores del ambiente, interesados en propagar el smog del odio, de la injuria y la calumnia. (DOONER, 1989, p. 14).

El "imperativo de la moderación" también era advertido de manera temprana por otros

${ }^{2}$ La traducción del fragmento es nuestra. 
analistas de la prensa, como Guillermo Sunkel, quien se preguntaba en 1991 si los medios habían apoyado el proceso de transición democrática o, por el contrario, si exhibían comportamientos editoriales e informativos disfuncionales al consenso político. Empleando la visión analítica propuesta por el académico uruguayo Héctor Borrat en su libro El periódico, actor político (1989), Sunkel relevaba que la prensa es, en efecto, un agente que ejerce su papel mediante la influencia, siendo el discurso su acción, en el que se presenta la doble faceta de narración y comentario de la realidad. (SUNKEL, 1991, p. 2). A partir de ello, identificaba tendencias de orientación a la acción, por parte de los periódicos, que se estaban ajustando crecientemente a las demandas de adecuación al modelo de transición por consenso.

En suma, a guisa de conclusión de esta primera parte de este artículo, es posible notar que los medios de prensa escrita, vehículos de formación y difusión de imaginarios sociales y transmisores de mensajes constitutivos de "emocionologías" contingentes a un determinado libreto histórico (en este caso, el de la transición como espacio de reconciliación nacional y enfriamiento del conflicto en todas sus dimensiones), buscaron cumplir su rol de entes performativos. Con ello se quiere señalar que su discurso tenía como misión instituir los bordes de la normalidad, de modo tal que esa operación tuviera implicancias prácticas en la conducta de los diversos actores mediante el viejo tópico de la "formación de la opinión pública".

Señalados ya brevemente los fundamentos del análisis, a continuación se presenta una mirada general al modo como algunos medios de prensa escrita buscaron construir un discurso respecto a un actor específico: el movimiento estudiantil universitario.

\section{Cuando no invisibles, molestos. Sobre algunas apariciones de los estudiantes en los medios escritos durante la transición}

Los procesos de transición hacia la democracia tras regímenes autoritarios suelen ser terreno hostil para los actores sociales que han desplegado esfuerzos sostenidos contra las dictaduras que les sirven de antecedentes. En términos generales (como se ha indicado ya al hacer referencia al clima emocional de consenso promovido en el Chile post Pinochet) sucede que las agendas políticas se articulan de manera tal que determinados grupos, cuyo protagonismo era crucial en períodos de movilización social, pierden presencia, cohesión y también disminuye la cobertura que la prensa les brinda o, más aún, son elaborados mediáticamente como disfuncionales: es lo que le pasó al movimiento estudiantil chileno. En otros casos nacionales, distintos en tiempo y condiciones, este fenómeno se hizo presente. Así, por ejemplo, pese a las numerosas diferencias en los respectivos procesos, es pertinente notar que en la transición española a la democracia (a la que fue frecuente que se hicieran referencias como modelo durante la que Chile vivió luego del fin del régimen de Pinochet) los estudiantes universitarios, protagonistas de la activa movilización antifranquista, luego del acuerdo de conciliación entre los principales partidos políticos tras la muerte del Caudillo, dejaron de ser un símbolo de cambio político como lo fueron en los momentos más críticos de la lucha contra la dictadura franquista y solamente volvieron a articularse, esporádicamente, para oponerse a algunas normativas que afectaron a las universidades españolas en los primeros años de la transición. (RODRÍGUEZ TEJADA, 2015, p. 97). Por otra parte, en lo que se refiere específicamente al tratamiento de la prensa, resulta interesante considerar el caso 
de Ecuador donde, luego de la vuelta a la democracia en 1979, el movimiento estudiantil fue rotulado como un problema, junto con la universidad pública misma, por parte de medios de prensa interesados, durante la década de 1980, en promover políticas de disminución del gasto fiscal y el tamaño del Estado, así como privatizar el campo educativo. (CELI; MORENO, 2017). Se aprecia, pues, un discurso de condena al activismo estudiantil, continuidad de una larga tradición de medios periodísticos derechistas ecuatorianos, que puede encontrar algunas semejanzas con lo que sucedió años después en el Chile de la transición a la democracia.

El aparente eclipse del movimiento estudiantil en los años iniciales de la transición a la democracia debe ser enmarcado en importantes transformaciones sociales y culturales que Chile experimentó en esa etapa. No sería errado considerar que el retroceso de las urgencias políticas, producto del acuerdo entre la oposición triunfante y los herederos de la dictadura (Pinochet incluido), permitió considerar con mayor rigor las transformaciones culturales que se habían operado en el país. De tal suerte, en noviembre de 1991, el siempre perspicaz sociólogo Manuel Antonio Garretón advertía respecto a algunas de ellas que ya se apreciaban o se irían notando crecientemente en la sociedad chilena. Relevaba las nuevas formas que tomaría el conflicto generacional, que

no es propiamente conflicto, por cuanto no hay este campo o problemática común. Los
jóvenes "están en otra" o "no están ni ahí" o "no pescan" a las otras generaciones. Y
este lenguaje, tomado de los jóvenes, que no es el del conflicto, enfrentamiento o
cooperación, sino el de la distancia insalvable entre mundos distintos, me parece
totalmente nuevo y marcador de una nueva cultura juvenil. (GARRETÓN, 1992, p. 12).

Es claro que esa fractura tendría consecuencias en términos de potenciar las diferencias entre los imaginarios sociales que difundía la prensa escrita, por un lado, y la experiencia de las nuevas generaciones estudiantiles, situadas en un terreno de alta volatilidad de los códigos culturales supuestamente compartidos que, en el marco de la lucha contra Pinochet como elemento cohesionador, se expresaron en los medios escritos opositores a la dictadura.

La distancia insalvable destacada por Garretón iría siendo acompañada por una creciente desafección juvenil respecto a estructuras normativas como, por ejemplo, la Iglesia Católica. Ésta se vio involucrada en un portentoso giro de discurso, relegando a segundo plano temáticas de justicia social y derechos humanos (que habían marcado su agenda en tiempos dictatoriales) y se acopló a un énfasis en torno a la moral sexual, promovido desde el mismo Vaticano por un conservador Juan Pablo II. La síntesis de este nuevo acento se planteó en la carta pastoral Moral, juventud y sociedad permisiva, texto dado a conocer por el Obispo de Santiago, Carlos Oviedo Cavada, en 1991. Dando cuenta de este fenómeno, El Mercurio, en su edición del domingo 17 de marzo de 1991, con el título "La juventud requiere de una ayuda urgente" presentaba una entrevista a monseñor Cristián Caro, nuevo obispo auxiliar de Santiago, quien mostraba las nuevas prioridades de la Iglesia hacia un enfoque más preocupado en la sexualidad, al diagnosticar con preocupación que en los tiempos que corrían "los jóvenes se dejan llevar por cosas más inmediatas, por otros caminos".

La progresiva pluralización de opciones culturales y estilos de vida juvenil, potenciada por un inédito proceso de recuperación y crecimiento económico que experimentó el país 
durante la década de 1990, se vio acompañada de transformaciones de importancia respecto a la composición del estudiantado universitario. La matrícula de la Educación Superior, entre 1985 y 2007, se incrementó de 200.000 a 763.000 alumnos, siendo 1990 el hito que marcó la aceleración de esa expansión. (BRUNNER, 2015). Ello introdujo un nuevo perfil de estudiantes universitarios, para los que buena parte de la agenda de movilización adquiriría sentido en la medida que se vinculara con la resistencia frente a la expansión de los mecanismos de mercado en el sistema universitario y el debilitamiento de las universidades estatales. En el campo opuesto, El Mercurio (vocero periodístico de los defensores del sistema económico creado en dictadura) identificaba tempranamente la necesidad de, a su juicio, dejar operar libremente al mercado universitario. En su editorial del jueves 8 de marzo de 1990, se sostenía que "nada parece justificar, como lo han sugerido algunos, una intervención del Estado tendiente a planificar centralmente la oferta de vacantes".

En un escenario adverso, aquellas fuerzas políticas estudiantiles que habían sido protagónicas en los años anteriores se veían sometidas a opciones muy poco auspiciosas para la autonomía y cohesión del movimiento (dada la cooptación que la Concertación estaba ejerciendo sobre su ala izquierda, que involucraba a un amplio espectro de fuerzas socialistas). En la temprana transición fue posible notar que los despliegues de movilización estudiantil de los grupos más activos y menos cooptados tomaron, principalmente dos formas. La primera de ella tuvo que ver con acciones reivindicativas frente a problemas de financiamiento estudiantil, como sucedió en 1992 cuando los alumnos de la Universidad de Chile ocuparon varias sedes universitarias para forzar a que se dieran negociaciones con la autoridad, tras lo cual vino un proceso de desmovilización estudiantil. (BOREN, 2001, p. 222). El segundo camino fue de orden más bien testimonial y consistió en que un sector de una fragmentada "izquierda radical se mantuvo participando o apoyando las acciones directas de cortes de calles y enfrentamientos con carabineros con piedras y bombas molotov, y a veces incluso, utilizando armas de fuego". (THIELEMANN, 2006, p. 82). Adoptando un repertorio de acción centrado en la performance de la violencia aguda, esta segunda vía tendió a derivar en un ritual prisionero de sus propias limitaciones, predecible, autocomplaciente y alienador para efectos de la rearticulación de movimientos de mayor alcance tanto numérico como estratégico.

En lo que respecta al discurso periodístico sobre el movimiento estudiantil, la segunda vía que hemos señalado ayudó a consolidar un tópico que le brindó alto rendimiento y permanencia: la figura del encapuchado como mal social y amenaza a la estabilidad. Desde el campo estudiantil y ya a fines de la década, en 1999, Mabel, alumna universitaria, señalaba acusatoriamente que, en los inicios de la transición, se desarrolló una reacción en cadena de los medios de comunicación frente a las manifestaciones universitarias:

Hubo un momento en que en todas las universidades del país surgen encapuchados. En la opinión pública hay una condena al acto en sí (encapucharse) pero simpatizan y adhieren a la causa del estudiantado. (SOTO, 2000, p. 13).

No es fácil de establecer cuán acertado era el diagnóstico de Mabel respecto al efecto político cohesionador que habrían tenido los encapuchados dentro del mundo político de los 
universitarios en los primeros años de la transición. Lo que sí resulta más claro es que los medios escritos tendieron a acompañar, a través de sus páginas, el ritual de los encapuchados, dando pie a una reiteración en el tiempo de una suerte de género informativo específico: el reportaje de incidentes violentos en espacios acotados. Con cobertura fotográfica ad hoc, La Tercera (medio periodístico con orientación menos derechista y más popular que El Mercurio) en su edición del 13 de septiembre de 1991 informaba sobre "15 detenidos en incidentes" tras enfrentarse a carabineros en las inmediaciones de la Universidad Metropolitana de Ciencias de la Educación (en la emblemática zona de Avenida Grecia y Macul, en que frecuentemente había barricadas de los estudiantes más radicalizados). Los hechos habían sucedido el día anterior luego de la conmemoración de un aniversario más del Golpe de Estado (día que, vale la pena agregar, en esos años todavía era feriado legal).

Una revisión panorámica de los principales medios de prensa durante los años 90 arroja, de acuerdo a lo recién indicado, hitos rutinarios que, por su repetición y solidaridad semántica como cadena de significados (violencia, desorden, capuchas, piedras, enfrentamientos), puede entenderse que formó parte de la naturalización y simplificación de las acciones de protesta y movilización de los estudiantes universitarios. Núcleos de dicha rutina fueron ciertas fechas específicas, en que los encapuchados devenían en la cara pública del estudiantado, de acuerdo a la cobertura que brindaban los periódicos. Cada 29 de marzo se ponía en escena una performance de combate callejero entre estudiantes radicalizados y las fuerzas policíacas, a propósito del "día del Joven Combatiente", conmemoración de la muerte de los hermanos Vergara Toledo, jóvenes militantes del MIR asesinados por carabineros en esa fecha en 1985 en la combativa Villa Francia, en la zona poniente de Santiago. Cabe señalar, como un síntoma de la precarización de la agenda propiamente universitaria de la izquierda radical, el hecho de que la muerte de ambos jóvenes tenía que ver más bien con la lucha política de los pobladores contra la dictadura que con el ámbito de las luchas estudiantiles. Como complemento, la agenda de este encuentro entre rituales de violencia política estudiantil y construcción mediática del miedo ante los encapuchados tuvo como otro de sus hitos fundamentales a las conmemoraciones en torno al aniversario del Golpe de Estado del 11 de septiembre de 1973 que, año tras año, establecieron las condiciones de posibilidad para aportar, mediante la prensa, a la elaboración de un imaginario social respecto al movimiento estudiantil.

Paralelamente a estos fenómenos, durante la primera mitad de la década de 1990 el movimiento estudiantil tendió a decaer seriamente en su capacidad para establecer en la agenda pública temas que incidieran en el debate nacional. Dando una mirada retrospectiva a la situación de las organizaciones estudiantiles universitarias, los periodistas Ana María Morales y Fernando Sagredo se preguntaban “¿qué pasó con el protagonismo estudiantil?", titulando así un reportaje publicado en el diario oficialista La Nación, en su edición del 17 de noviembre de 1996. Constataban que, en el caso de la Federación de Estudiantes de la Universidad de Chile (FECH) la organización "pasó a ser una gran patrocinadora de eventos, actividades que fueron acompañadas de todo tipo de campañas: ecológicas, de educación sexual, contra el sida, contra el servicio militar obligatorio, entre muchas otras" pero que, en el plano de la disputa política y la participación masiva de estudiantes, se experimentó una crisis 
que condujo a la disolución de la FECH en 1994 debido a problemas de apropiación indebida de fondos por parte de algunos de sus dirigentes. Así, el grueso de los estudiantes en busca de organización se veía sumergido, en los primeros años de la década, más que en la continuidad de sus antiguas plataformas partidistas de pertenencia, en búsqueda de nuevas formas de participación: una franja de universitarios de izquierda que no era militante, ni organizada, sino más bien el fruto de una especie de "estado de ánimo" que les hizo converger con otros actores, en el contexto de la crisis de financiamiento e institucional que vivía la Universidad de Chile a mediados de la década de los '90. (MORAGA, 2006, p. 212). Este proceso, más bien orientado "hacia adentro", mereció poca atención de parte de la prensa escrita, salvo en la medida que involucrara acciones de fuerza, dirigidas contra las autoridades institucionales de cada universidad como también frente al gobierno.

Cuando se plantearon situaciones críticas en el campo universitario y que involucraron manifestaciones estudiantiles, a propósito de problemas de orden económico, los universitarios "no encapuchados" volvieron a figurar en las páginas de los diarios, dando pábulo al despliegue de un discurso crítico hacia el movimiento estudiantil y promotor de la adhesión al orden y paz social. En los primeros meses del segundo gobierno de la Concertación, encabezado por Eduardo Frei Ruiz-Tagle, la periodista Claudia Cento, del diario La Tercera, daba a conocer (en reportaje publicado el miércoles 16 de marzo de 1994), la disputa existente por el cambio en las modalidades de cobro de aranceles, que incluía el uso de letras de cambio y el pago en UF (unidades de valor reajustables, que despertaba la oposición de los estudiantes). Informaba, además, de la prolongación de una toma estudiantil de la torre central de la Facultad de Ingeniería de la Universidad de Chile. En la nota de prensa se indicaba, de todas maneras, que la medida de fuerza estaba enmarcada en "un ambiente de jolgorio, en el que no faltó la música, el deporte y hasta la elección de la reina del paro", quizás intentando restarle dramatismo (o seriedad) al fenómeno. No fue un ánimo compartido por Tito Justo Livio, seudónimo del periodista Héctor Olave, uno de los principales redactores de La Tercera). Olave, dueño de una larga trayectoria periodística que incluía experiencia laboral en El Mercurio, planteaba una carta a los "Estimados estudiantes en paro de la U de Chile", publicada el viernes 18 de marzo de 1994, en la que, en tono paternal y admonitorio, les reprendía pues

tomarse las sedes de sus escuelas o realizar actos que violentan la tranquilidad ciudadana y hasta lesionan el prestigio del estudiantado universitario, no es una manera adecuada de resolver esa ni otra dificultad". Se "ustedes son jóvenes y por ello no vivieron experiencias traumatizantes como las que sufrimos en un pasado no muy lejano los que tenemos más edad [...] De ahí que les diga que si ustedes insisten en reeditar episodios que el país desea mantener solo en su historia, estarán colaborando a que Chile vuelva a caer en situaciones divisionistas y en nada ayudarán a resolver sus conflictos. (OLAVE, 1994).

El conflicto fue desactivado por el rector de la Universidad de Chile, Jaime Lavados, quien decidió anular los cambios propuestos en el sistema de cobros de aranceles a los estudiantes. Resulta llamativa la reacción que tuvo La Tercera, frente a la medida del rector. En "Marzo caliente", una breve nota de la sección "pasillo político" de ese diario, publicada el sábado 19 de marzo de 1994, se reprochó la flexibilidad de la autoridad universitaria 
recordando (con cierto tono apocalíptico) que "hace 26 años, en Francia, un 22 de marzo, se abrió la protesta estudiantil más tumultuosa del siglo, que culminó con la "semana rabiosa de mayo del 68" [...] Los errores políticos, frente al estudiantado, se pagan caro". Como contraste, a guisa casi de modelo ofrecido a los lectores, el mismo periódico resaltaba al día siguiente, con tonos amables y empáticos, las iniciativas de la Federación de Estudiantes de la Universidad Católica (Feuc). Bajo el título "Estudiantes de la UC inician semana novata", en la edición del domingo 20 de marzo de 1994, se describía cómo, siguiendo su línea histórica de declarado (y supuesto) apoliticismo, el gremialismo en la Universidad Católica daba a conocer, en voz del presidente de Feuc, Alejandro San Francisco, las prioridades que tendría como organización estudiantil. En una nota periodística encabezada por la foto de las candidatas a reina universitaria, cuatro atractivas jovencitas de raigambre patricia, se afirmaba que Feuc se enfocaría en "el bienestar estudiantil y la excelencia académica, sin dejar al margen la entretención, la diversión, el deporte y la integración de los estudiantes que se dan en actividades como la programada [la Semana Novata, de bienvenida a los nuevos estudiantes]".

El episodio recién mencionado es sintomático de ciertos patrones de respuesta de parte de la prensa frente a situaciones de conflicto generadas por los estudiantes universitarios. La rápida invocación al pasado como trauma fundante y tabú, en términos de ser amenaza de la persistencia de la violencia generalizada de la que el país quería huir, fue un recurso empleado para desestimar la legitimidad de formas de acción que involucraran algún grado de violencia (manifestaciones callejeras, paros y tomas de espacios universitarios). También fue una invocación al pasado temido lo que se manifestó, por otros medios, en un conflicto de tono distinto, ya en la segunda mitad de la década. Tras el colapso de la FECH en 1994, la principal federación estudiantil ya estaba en proceso de rearticulación en 1995. Con ello, aunque desde una base de formas de organización política universitaria bastante distintas a la que había existido en el movimiento estudiantil de fines de la dictadura e inicios de la transición, se reactivó la presencia masiva ( $y$, por ende, mediática) de los universitarios. La resurrección de la FECH despertó en la prensa cierto desasosiego, sobre todo considerando que el nuevo presidente de la organización, Rodrigo Roco, pertenecía a las Juventudes Comunistas (J. J. C. C.), lo que activó un prurito anticomunista, ingrediente de la construcción del imaginario social heredado de la dictadura y proyectado en la transición. A mediados de 1996 el movimiento estudiantil volvía a tener una presencia callejera masiva: un paro nacional universitario interrumpió el funcionamiento de la mayoría de las instituciones de educación superior y los estudiantes desplegaron una muy nutrida marcha por la Alameda. Tiempo después, acusando recibo de esta reaparición de la masividad de las manifestaciones de los universitarios, el diario El Mercurio reconocía preocupadamente, en su edición del 7 de junio de 1997, que

Lo que en un momento pareció ser únicamente una postura extrema de la FECH y de algunos sectores del alumnado exigiendo profundas reformas y la salida de Jaime Lavados, de pronto se trasformó en una solicitud visceral de casi la totalidad de los universitarios. Esa tarde, el otrora poderoso movimiento estudiantil de la Universidad de Chile pareció resucitar. (MUÑOZ TAMAYO, p. 333).

A mediados de 1997 el movimiento estudiantil, reformulado en sus estructuras de 
representación política (con preeminencia de colectivos y asambleas de estudiantes frente a las tradicionales juventudes de los partidos políticos históricos) tuvo oportunidad de sostener un ciclo de movilizaciones que, nuevamente, despertó intranquilidad en los medios escritos. El Mercurio, en tanto vocero de los grupos que apoyaban medidas racionalizadoras que buscaba impulsar el rector de la Universidad de Chile, se hizo eco de un discurso que buscó vincular la acción estudiantil con el pasado, remontándose incluso a los fantasmas (ya extintos) de la época de la reforma universitaria de la década de 1960. Así, frente a la (ya rutinaria) inclusión de la exigencia de participación de los alumnos en el manejo de las universidades como un punto de los pliegos de demanda del movimiento, se optó por relevar mediáticamente la amenaza del "cogobierno universitario". En esta operación había una muestra más de la histórica distancia existente entre este medio escrito y los estudiantes políticamente movilizados pues, en estricto sentido, el tema era secundario en la lista de prioridades de la Fech y no tenía, en el terreno de su estrategia política, carácter de irrenunciable. (MORAGA, 2006, p. 205).

En síntesis, puede apreciarse que en la primera parte de la década de transición la prensa escrita reflejó en escasa medida las transformaciones del movimiento estudiantil universitario, principalmente debido a que ellas eran de orden más bien interno, relativas a nuevas lógicas de organización, y porque hubo un reflujo generalizado de acciones estudiantiles, salvo en casos muy específicos vinculados a demandas de orden económico. Paralelamente, se presentaba periódicamente el rostro amenazador de "los sin rostro" (o sea, los encapuchados), en la medida que sus acciones de violencia aguda sintonizaban con un discurso de carácter general, bajo la idea matriz de "seguridad ciudadana", en que se las asociaba a delincuencia, terrorismo e inestabilidad. En cambio, tras el retorno de las movilizaciones masivas de los estudiantes universitarios a partir de 1996, el discurso periodístico tuvo que agregar otros elementos retóricos como, por ejemplo, la amenaza a la estabilidad de las instituciones universitarias a propósito de un eventual cogobierno.

Podría resumirse parte del efecto de estos discursos periodísticos en la construcción de un imaginario social teniendo a la vista lo que señalaba Sunkel en 1992, aludiendo a nociones fundamentales de la teoría sobre los medios de comunicación: ellos no son capaces de determinar totalmente qué piensan sus lectores pero sí de en qué lo hacen. O sea, mediante actos de selección intencionada de información relevada de acuerdo a criterios de agenda, ofrecían una visión acerca del movimiento estudiantil que, naturalmente, se sometía a distintos órdenes normativos, para el logro de los cuales se disponía de un repertorio amplio de recursos. Entre los más frecuentes estuvo, ciertamente, la apelación al miedo frente a la violencia y al retorno al pasado. Ella se vio acompañada por un énfasis en los rasgos disfuncionales del carácter juvenil (y por ende, pasional e irracional) de los estudiantes, siguiendo una tradición de análisis sobre los movimientos estudiantiles que tenía una larga data y que subrayaba al conflicto generacional como una matriz explicativa de la radicalidad estudiantil, rotulándola como "un complejo de impulsos - altruismo, idealismo, revuelta, auto sacrificio y autodestrucción”. (FEUER, 1971, p. 30). 


\section{Conclusiones}

En 1992 el sociólogo Guillermo Sunkel abordaba un problema que estaba convirtiéndose en foco de debate público: las posibles vinculaciones causales entre la práctica de los medios de comunicación y la expansión de la violencia, en el contexto de los inicios de la transición democrática en Chile. De acuerdo a la opinión de algunos sectores políticos, la prensa nacional estaba siendo víctima de los efectos de los nuevos marcos de la industria, en que la acostumbrada censura que imperó durante la dictadura militar cedía paso a una total libertad de información, la que los medios no lograban equilibrar todavía con las necesidades estratégicas del proceso de reconciliación nacional y apaciguamiento ciudadano que se buscaba promover desde el Estado y los distintos actores hegemónicos de la sociedad chilena. En tal sentido, se argumentaba que existía una suerte de "complicidad" de los medios informativos con la acción de grupos violentos o acciones delictuales. Especial énfasis se ponía, en el discurso de los grupos más críticos frente a este ejercicio (a su juicio) desregulado de la libertad de información, en la "complicidad involuntaria" que se habría producido por parte de medios que habrían caído en el error del "mimetismo con el lenguaje de las fuentes", sirviendo de canal de amplificación de grupos terroristas al emplear términos propios de éstos como, por ejemplo, "combatientes", "rescate" o "acción de apoyo", en vez de tomar distancia o usar palabras con connotación abiertamente condenatoria. (SUNKEL, 1992b, p. 66).

La discusión de la que daba cuenta Sunkel resume parte de los problemas que deben enfrentar países en procesos de transición luego de haber vivido dictaduras violentas y/o prolongadas, en las que distintos actores colectivos (como, por ejemplo, los estudiantes) experimentan roles que, de acuerdo a los criterios de la "normalidad política" que adviene con la democracia, deben ser reordenados y sometidos a nuevos parámetros de valoración. En tal sentido, los medios periodísticos (como se ha visto ejemplificado en estas páginas con El Mercurio y La Tercera) debieron acometer la tarea de reforzar los bordes de la normalidad como parte de su misión de instituir un imaginario social. Esa operación, que respondía al viejo tópico de la "formación de la opinión pública", presentó un perfil principalmente disfuncional respecto al movimiento estudiantil. Ahora bien, como suele suceder respecto a los actos comunicativos, es difícil establecer en qué medida los contenidos del discurso periodístico tuvieron los efectos esperados. En tal sentido, una observación atenta a la pluralidad de factores presentes en la configuración de los imaginarios sociales lleva a tomar distancia respecto a interpretaciones deterministas, unilaterales o a exagerar la capacidad de agencia de productores de discurso tales como la prensa.

Por último, cabe señalar que la construcción de una imagen, usualmente estereotipada, de las movilizaciones estudiantiles universitarias a lo largo de la década de 1990 estaba sometida a una tensión no menor: debía desplegar tales simplificaciones (estudiantes violentos, maximalismo de sus demandas, etc.) pero, sin embargo, también requería representar, en alguna medida, los cambios que, en efecto, estaban sucediendo tanto en el nivel global de la cultura del país como en el sistema universitario en específico, si deseaba ser un "espejo de la sociedad". No obstante, cumplir con esta segunda tarea involucraba instalar una mayor gama de matices en su discurso para, por ejemplo, comprender de mejor forma los poderosos cambios operados en el actor colectivo que eran el movimiento estudiantil. 
Implementar esa tarea era, en algún modo, ir más allá del horizonte del imaginario social hegemónico y buscar discernir sobre la índole de los nuevos estudiantes. Si bien los universitarios movilizados durante la década de 1990 no carecían de razones para experimentar miedo pese a la democracia (baste recordar que hubo estudiantes muertos en protestas como, por ejemplo, Daniel Menco, en la nortina ciudad de Arica en 1999), los jóvenes reclutados en ingentes cantidades en un sistema universitario en expansión acelerada, buscaron hacer visibles sus nuevos demonios, frente a una prensa que, frecuentemente, optó por hacerlos invisibles o asociarlos a la violencia sin sentido. Los nuevos enemigos del movimiento universitario ya no tenían que ver con la persona de un dictador sino que con enfrentarse a las "incertidumbres propias de un tipo de sociedad amenazante: miedo a la cesantía, al empleo precario, a las carencias en salud o previsión. Miedo a la soledad. Y, conforme esos miedos, también la ira se reordenó en sus coordenadas de destino: ira frente a la desigualdad y la exclusión" (TORO BLANCO, 2017), asuntos a los que los medios tendrían que conceder atención en lo sucesivo si pretendían articular discursos de imaginarios sociales de tranquilidad, progreso y reconciliación con los acelerados cambios que experimentó el país durante esa década.

\section{Referencias}

BOREN, Mark Edelman. Student resistance. The history of the unruly subject. New York: Routledge, 2001.

BRUNNER, José Joaquín. Medio siglo de transformaciones de la educación superior chilena: Un estado del arte. In: BERNASCONI, Andrés (Ed.). La educación superior de Chile:

Transformación, desarrollo y crisis. Santiago: Ediciones Universidad Católica de Chile, 2015. p. 21-108.

CAVALLO, Ascanio. Escribiendo con el enemigo. In: CAVALLO, Ascanio; CEBRIÁN, Juan Luis; HEPP, Ricardo; SANTIBAÑEZ, Abraham. Periodismo y democracia. Santiago: Uqbar Editores, 2014. p. 73-97.

CELI, Carlos; MORENO, Kintia. Construcción de la negatividad: Universidad Central del Ecuador y movimiento estudiantil a los ojos del diario El Comercio (1980-1996). In: MARSISKE, Renate (Coord.). Movimientos estudiantiles en la historia de América Latina V. Ciudad de México: CESU-UNAM, 2017. p. 251-313.

DIBAM. 50 años de prensa chilena. Santiago: DIBAM, 2016.

DITTUS, Rubén. El Imaginario Social y su aporte a la Teoría de la Comunicación: seis argumentos para debatir. Santiago: Ediciones Universidad Católica Silva Henríquez, 2008.

DOONER, Patricio. Periodismo y política. La prensa de derecha e izquierda, 1970-1973. Santiago: Editorial Andante, 1989.

DOUGNAC, Paulette et al. El diario de Agustín. Cinco estudios de casos sobre El Mercurio y los derechos humanos (1973-1990). Santiago: LOM, 2009.

FEUER, Lewis. Los movimientos estudiantiles. Las revoluciones nacionales y sociales en Europa y el Tercer Mundo. Buenos Aires: Paidós, 1971.

FREVERT, Ute. Emotions in history: lost and found. Budapest: Central European University Press, 2011. 
GARRETÓN, Manuel Antonio. Cambio cultural y familia. Reflexiones preliminares. In: GARRETÓN, Manuel Antonio. Transformación cultural. Cuatro documentos de reflexión preliminar. Santiago: Flacso, 1992 [Documento de Trabajo n. 25].

GUMUCIO, Manuela; PARRINI, Vicente. Política comunicacional de la Concertación. In: QUIROGA, Yesko; ENSIGNIA, Jaime (Coords.). Chile en la Concertación (1990-2010). Santiago: Friedrich Ebert Stiftung, 2009. p. 301-331.

IGGERS, Georg. La historiografía del siglo XX. Desde la objetividad científica al desafío posmoderno. Santiago: Fondo de Cultura Económica, 2012.

MARÍN NARITELLI, Francisco. Las batallas por la Alameda. Arteria del Chile demoliberal. Santiago: Ceibo Ediciones, 2014.

MORAGA, Fabio. Crisis y recomposición del movimiento estudiantil chileno. In: MARSISKE, Renate (Coord.). Movimientos estudiantiles en la historia de América Latina III. Ciudad de México: CESU-UNAM, 2006. p. 179-252.

MUÑOZ TAMAYO, Víctor. Generaciones. Juventud universitaria e izquierdas políticas en Chile y México (Universidad de Chile - UNAM 1984-2006). Santiago: LOM, 2012.

RODRÍGUEZ TEJADA, Sergio. Anti-Franco student movement's contribution to the return of democracy in Spain. Espacio, Tiempo y Educación, 2 (2), p. 77-106, 2015.

SANTA CRUZ, Eduardo. Prensa y sociedad en Chile, siglo XX. Santiago: Editorial Universitaria, 2015.

SOTO, Rodrigo. La estética de la capucha (o el reencuentro de la subjetividad política). In: COLECTIVO LITERARIO LA CÓPULA, Los andamios de la ira. Ediciones La Cópula: Santiago, 2010. p.11-15.

STEARNS, Peter; STEARNS, Caroline. Emotionology: Clarifying the History of Emotions and Emotional Standards. The American Historical Review, 90 (4), p. 813-836, 1985.

SUNKEL, Guillermo. La Prensa en la Transición Chilena. Santiago: Flacso, 1992a. [Documento de Trabajo n. 26].

. Medios de comunicación y violencia en la transición chilena. In: Cuadernos del Foro '90. Estado y seguridad ciudadana. Santiago: CINDE, 1992b, p. 57-104 Trabajo n. 15].

Prensa y Opinión Pública en la Transición. Santiago: Flacso, 1991. [Documento de

TAYLOR, Charles. Imaginarios sociales modernos. Barcelona: Paidós, 2006.

THIELEMANN, Luis. "La anomalía social de la transición". Movimiento estudiantil e izquierda universitaria en el Chile de los '90 (1987-2000). Santiago de Chile: Tiempo Robado Editoras, 2016.

TORO BLANCO, Pablo. De miedo y de ira: estudiantes universitarios y emociones en dictadura e inicios de la transición chilena (c. 1983 - c. 1998). In: CORDERO, Macarena (Ed.). Rastros y registros de las emociones. Santiago: Universidad Adolfo Ibáñez, 2017 (en prensa). 
PABLO TORO BLANCO é professor na Universidad Alberto Hurtado, Doutor em História pela Pontificia Universidad Católica de Chile.

Endereço: Avenida Libertador Bernardo O'Higgins, 1869 - Santiago - Chile.

E-mail: ptoro@uahurtado.cl

Recebido em 26 de outubro de 2017.

Aceito em 28 de novembro de 2017. 